\title{
Prevention and management of severe pre-eclampsia/eclampsia in Afghanistan
}

\author{
Young Mi Kim ${ }^{1 *}$, Nasratullah Ansari ${ }^{2}$, Adrienne Kols ${ }^{1}$, Hannah Tappis ${ }^{3}$, Sheena Currie ${ }^{1}$, Partamin Zainullah²,
} Patricia Bailey ${ }^{4}$, Jos van Roosmalen ${ }^{5}$ and Jelle Stekelenburg ${ }^{6}$

\begin{abstract}
Background: An evidence-based strategy exists to reduce maternal morbidity and mortality associated with severe pre-eclampsia/eclampsia (PE/E), but it may be difficult to implement in low-resource settings. This study examines whether facilities that provide emergency obstetric and newborn care (EmONC) in Afghanistan have the capacity to manage severe PE/E cases.
\end{abstract}

Methods: A further analysis was conducted of the 2009-10 Afghanistan EmONC Needs Assessment. Assessors observed equipment and supplies available, and services provided at 78 of the 127 facilities offering comprehensive EmONC services and interviewed 224 providers. The providers also completed a written case scenario on severe PE/E. Descriptive statistics were used to summarize facility and provider characteristics. Student t-test, one-way ANOVA, and chi-square tests were performed to determine whether there were significant differences between facility types, doctors and midwives, and trained and untrained providers.

Results: The median number of severe PE/E cases in the past year was just 5 (range 0-42) at comprehensive health centers (CHCs) and district hospitals, compared with 44 (range 0-130) at provincial hospitals and 108 (range 32-540) at regional and specialized hospitals ( $p$ 0.001). Most facilities had the drugs and supplies needed to treat severe $\mathrm{PE} / \mathrm{E}$, including the preferred anticonvulsant, magnesium sulfate $\left(\mathrm{MgSO}_{4}\right)$. One-third of the smallest facilities and half of larger facilities reported administering a second-line drug, diazepam, in some cases. In the case scenario, $96 \%$ of doctors and $89 \%$ of midwives recognized that $\mathrm{MgSO}_{4}$ should be used to manage severe PE/E, but $42 \%$ of doctors and $58 \%$ of midwives also thought diazepam had a role to play. Providers who were trained on the use of $\mathrm{MgSO}_{4}$ scored significantly higher than untrained providers on six of 20 items in the case scenario. Providers at larger facilities significantly outscored those at smaller facilities on five items. There was a significant difference between doctors and midwives on only one item: continued use of anti-hypertensives after convulsions are controlled.

Conclusions: Drugs and supplies needed to treat severe PE/E are widely available at EmONC facilities in Afghanistan, but providers lack knowledge in some areas, especially concerning the use of $\mathrm{MgSO}_{4}$ and diazepam. Providers who have specialized training or work at larger facilities are better at managing cases of severe PE/E. The findings suggest a need to clarify service delivery guidelines, offer refresher training, and reinforce best practices with supervision and reinforcement.

Keywords: Pre-eclampsia, Eclampsia, Magnesium sulfate, Emergency obstetric care, Afghanistan

\footnotetext{
* Correspondence: Young-Mi.Kim@jhpiego.org

'Jhpiego/USA, an affiliate of Johns Hopkins University, 1615 Thames Street, Baltimore, MD 21231, USA

Full list of author information is available at the end of the article
} 


\section{Background}

The World Health Organization (WHO) estimates that at least $16 \%$ of maternal deaths in low- and middle-income countries result from hypertensive disorders of pregnancy, including severe pre-eclampsia and eclampsia (PE/E) [1]. Clinical indications of pre-eclampsia typically present as high blood pressure and protein in the urine after 20 weeks gestation. Eclampsia is diagnosed when a pregnant woman with pre-eclampsia develops convulsions [2]. Although there are known risk factors for hypertensive disorders of pregnancy, there is no clinically useful way to predict which women will develop pre-eclampsia based on clinical data or biochemical markers [3]. However, high-income countries have been able to reduce both the incidence of eclampsia and the case fatality rate associated with it by $90 \%$, using a combination of early detection during antenatal care (ANC) and increased access to hospital care for women who develop severe PE/E [4]. Comparable reductions in rural China and Sri Lanka suggest that this model-which includes routinely screening pregnant women for hypertension and proteinuria, treating severe $\mathrm{PE} / \mathrm{E}$ with anti-hypertensive and anticonvulsant drugs, and, if necessary, ending the pregnancy early by inducing labor or conducting cesarean delivery-can be applied in low-income countries [5].

Implementing this strategy in a low-resource setting is challenging, however. First, it requires good quality focused ANC for all pregnant women in order to detect cases of severe PE/E, along with increased awareness of danger signs among women and the community. Since $\mathrm{PE} / \mathrm{E}$ can occur during pregnancy, labor, or postpartum, it is important that detection efforts begin in pregnancy and continue through labor and the postpartum period. Second, it demands the presence of skilled birth attendants at antenatal clinics and during births, with ready access to emergency obstetric and newborn care (EmONC). Managing eclampsia with anticonvulsants is one of nine essential EmONC services-called signal functions-that directly prevent and/or treat complications associated with maternal and newborn death. Indeed, routine screening only makes sense when women diagnosed with severe pre-eclampsia can be referred to EmONC facilities that have skilled personnel, supplies, and equipment needed to treat the condition and induce labor [6]. Finally, addressing severe $\mathrm{PE} / \mathrm{E}$ requires adequate and reliable supplies of equipment and drugs-to measure blood pressure, test for proteinuria, and treat $\mathrm{PE} / \mathrm{E}$ - at every level of the health system [4]. Magnesium sulfate $\left(\mathrm{MgSO}_{4}\right)$ is critical, because it is the drug of choice for preventing convulsions in preeclamptic women and for preventing recurrence of convulsions [7]. Multi-center trials have demonstrated that this anticonvulsant, which is inexpensive and does not require special storage, is significantly more effective than diazepam or other drugs in reducing convulsions, preventing progression from severe pre-eclampsia to eclampsia, and improving outcomes for mothers and newborns [8-10].

In Afghanistan-where the maternal mortality ratio is high at 327 deaths per 100,000 live births and hypertensive disorders of pregnancy account for $20 \%$ of maternal deaths [11] - reducing morbidity and mortality from severe $\mathrm{PE} / \mathrm{E}$ will require systematic changes in women's health-seeking behaviors and access to health care, as well as an increase in the capacity of the health system to offer ANC and EmONC services. In a recent national survey, just $48 \%$ of Afghan women (77\% in urban areas and $41 \%$ in rural areas) reported receiving ANC from a skilled provider and only $15 \%$ made at least four ANC visits, as recommended by WHO [12]. According to women's reports, ANC providers were not likely to measure blood pressure or take urine samples $(35 \%$ and $24 \%$, respectively). Only one-third of Afghan women delivered in health facilities (66\% urban, 25\% rural), and 39\% were attended by skilled providers (74\% urban, 31\% rural).

In Afghanistan's tiered health system, health posts, basic health centers, and comprehensive health centers ( $\mathrm{CHCs}$ ) offer basic curative and preventive services at the community level. The district hospital (or $\mathrm{CHC}$ where no district hospital exists) serves as the link between primary care facilities and the network of referral hospitals. The sophistication level of health infrastructure and services increases from district hospitals to provincial and regional hospitals to national specialty hospitals. The Ministry of Public Health of Afghanistan (MoPH) has designated 127 health facilities to provide comprehensive EmONC services, including all district, provincial, and regional hospitals, as well as national hospitals specializing in maternity care and certain $\mathrm{CHCs}$ in remote areas.

This study examines one part of the strategy to reduce morbidity and mortality from PE/E in Afghanistan: improving the treatment of severe $\mathrm{PE} / \mathrm{E}$. We performed a further analysis of the 2009-10 Afghanistan Emergency Obstetric and Newborn Care Needs Assessment [13] to evaluate the capacity of EmONC facilities and their providers to manage severe $\mathrm{PE} / \mathrm{E}$ cases.

\section{Methods}

In 2009-10, a needs assessment sought to examine EmONC services at all 127 designated EmONC facilities; however, 49 of those facilities (16 CHCs, 25 district hospitals, five provincial hospitals and three national specialty hospitals) were not accessible due to security constraints [14]. The remaining 78 facilities constitute the study sample. They include nine $\mathrm{CHCs}, 34$ district hospitals, 25 provincial hospitals, five regional hospitals, and five national specialty hospitals. Two-thirds of the facilities are located in urban areas. Although the study covered only $61 \%$ of the government health facilities expected to provide 
comprehensive EmONC services, it included facilities in 31 of Afghanistan's 34 provinces and assessed all facilities in secure areas where it is possible for international nongovernmental organizations (NGOs) to implement health programs and conduct research. Two doctors and two midwives responsible for providing EmONC services were randomly selected to participate in the study at each provincial, regional, and specialty hospital. Two providers, including a doctor if one was available, were chosen to participate at each district hospital and $\mathrm{CHC}$.

The assessment team consisted of six doctors and 38 midwives. All were experienced service providers and had helped collect data for previous studies in Afghanistan. The assessors had one week of training, after which intraand inter-assessor reliability were tested. They visited each facility for one to three days to collect data. Health facilities were not informed in advance about the assessors' visit. Upon arrival at each facility, assessors obtained consent from the facility's Medical Director and held an introductory meeting with key informants, including staff in charge of maternity, surgery, pharmacy, and laboratory departments.

To investigate the facility's capacity to provide ANC, labor, and delivery services, assessors made observations, interviewed key informants, and reviewed records, using tools based on a Needs Assessment Toolkit developed by the Averting Maternal Death and Disability (AMDD) Program [15]. Assessors also interviewed providers regarding their training on and experience with focused ANC and treatment of severe PE/E. A written case scenario was used to evaluate providers' knowledge and clinical judgment regarding severe PE/E. The case scenario described a pregnant woman brought to the emergency department of a district hospital after experiencing convulsions at home. At each step in the scenario, providers were asked how the case should be managed; they selected appropriate actions from a list of possible options. The percentage of providers who selected each correct response was calculated. The case scenario instrument shows exactly what background information was given to providers, along with the questions and a list of all possible answers [see Additional file 1].

The MoPH and National Reproductive Health Task Force adapted AMDD observation, interview, and record review tools for use in this study. They then led a workshop to review and revise the tools with national EmONC trainers and experts from UNICEF, WHO, and NGOs contracted by the MoPH to operate primary health facilities. The PE/E case scenario was developed separately by international experts at the Maternal and Child Health Integrated Program (MCHIP). All tools, including the case scenario, were pilot tested in Afghanistan during the assessors' training workshop. The study protocols were approved by the Institutional Review Boards of the
Afghanistan Public Health Institute and the Johns Hopkins School of Public Health (IRB 2333 and IRB 2359).

Descriptive statistics were used to summarize facility and provider characteristics. Student t-test, one-way ANOVA, and chi-square tests were performed to determine whether there were significant differences between types of facilities, doctors and midwives, and trained and untrained providers. Analyses were conducted using STATA 11.2 with a type 1 error of 0.05 .

\section{Results \\ Caseloads, supplies, and drugs}

The number of women with severe $\mathrm{PE} / \mathrm{E}$ treated at EmONC facilities varied widely. The median number of severe PE/E cases in the past year was just 5 (range 0-42) at $\mathrm{CHCs}$ and district hospitals, compared with 44 (range $0-130)$ at provincial hospitals and $108(32-540)$ at regional and specialized hospitals $(\mathrm{p}<0.001)$ (Table 1$)$. This reflects variations in the size and caseload at different types of EmONC facilities: the median number of vaginal deliveries documented in maternity ward logbooks ranged from 1,078 (range 76-7,002) deliveries per year at CHCs and district hospitals to 7,516 (range 920-43,772) at provincial hospitals and 35,182 (range 6,368-82,124) at regional and specialized hospitals.

On the day of the survey, pertinent service delivery guidelines were available in $83.7 \%$ to $100 \%$ of facilities (Table 1). Blood pressure cuffs and stethoscopes were available at all facilities, and three-fifths had urine test strips to check for proteinuria. From $76.7 \%$ to $96 \%$ of facilities had a complete IV set to maintain fluid balance and administer antihypertensives and $\mathrm{MgSO}_{4}$. There were no significant differences in the availability of any of these items by facility type. All but one $\mathrm{CHC}$, one district hospital, and three provincial hospitals had anti-hypertensive drugs in stock.

Anticonvulsants were widely available, although not always used. $\mathrm{MgSO}_{4}$ was in stock at all regional and specialized hospitals and over $93 \%$ of other facilities. Diazepam was almost as widely available, except at regional and specialized hospitals. With one exception, all facilities had administered the preferred anticonvulsant, $\mathrm{MgSO}_{4}$. However, $33 \%$ of $\mathrm{CHCs}$ and district hospitals, $56 \%$ of provincial hospitals, and $50 \%$ of regional and specialized hospitals had administered diazepam in some cases as well. Only one facility (a provincial hospital) reported administering diazepam but not $\mathrm{MgSO}_{4}$. Of the $10 \mathrm{CHCs}$ and district hospitals that had not recently administered anticonvulsants, six reported that no women had required it and three did not give any reason. Lack of supplies and equipment, training issues, and availability of human resources were additional reasons given for not administering anticonvulsants. 
Table 1 PE/E caseload, supplies, and equipment at health facilities, by facility type

\begin{tabular}{|c|c|c|c|c|}
\hline Item & $\begin{array}{l}\text { CHCs and district } \\
\text { hospitals }(n=43)\end{array}$ & $\begin{array}{r}\text { Provincial } \\
\text { hospitals }(n=25)\end{array}$ & $\begin{array}{r}\text { Regional and specialized } \\
\text { hospitals }(n=10)\end{array}$ & p-value \\
\hline \multicolumn{5}{|l|}{ No. of vaginal deliveries in last 12 months } \\
\hline Median & 1,078 & 7,516 & 35,182 & $<0.001$ \\
\hline Range & $76-7,002$ & $920-43,772$ & $6,368-82,124$ & \\
\hline \multicolumn{5}{|l|}{ No. of $\mathrm{PE} / \mathrm{E}$ cases in last 12 months } \\
\hline Median & 5 & 44 & 108 & $<0.001$ \\
\hline Range & $0-42$ & $0-130$ & $32-540$ & \\
\hline At least one $\mathrm{PE} / \mathrm{E}$ case treated in past 3 months (\%) & 72.1 & 100.0 & 100.0 & 0.003 \\
\hline \multicolumn{5}{|l|}{ Guidelines present in maternity ward (\%) } \\
\hline Focused ANC & 88.4 & 92.0 & 100.0 & 0.500 \\
\hline Management of obstetric complications & 83.7 & 88.0 & 100.0 & 0.378 \\
\hline \multicolumn{5}{|l|}{ Supplies and equipment available (\%) } \\
\hline BP cuff and stethoscope & 100.0 & 100.0 & 100.0 & 1.000 \\
\hline Urine test strips & 62.8 & 64.0 & 60.0 & 1.000 \\
\hline Complete IV set $^{\mathrm{a}}$ & 76.7 & 96.0 & 80.0 & 0.088 \\
\hline Any anti-hypertensive available (\%) & 95.4 & 88.0 & 100.0 & 0.404 \\
\hline \multicolumn{5}{|l|}{ Anticonvulsants available (\%) } \\
\hline $\mathrm{MgSO}_{4}$ & 93.0 & 96.0 & 100.0 & 1.000 \\
\hline Diazepam & 90.7 & 96.0 & 70.0 & 0.090 \\
\hline $\begin{array}{l}\text { Among facilities that administered anticonvulsants } \\
\text { in last } 3 \text { months, drugs (\%) used }\end{array}$ & $(n=33)$ & $(n=25)$ & $(n=10)$ & \\
\hline $\mathrm{MgSO}_{4}$ only & 66.6 & 40.0 & 50.0 & 0.449 \\
\hline Diazepam only & 0 & 4.0 & 0 & \\
\hline Both drugs & 33.3 & 56.0 & 50.0 & \\
\hline
\end{tabular}

Includes IV cannulae, catheter for IV line, and IV infusion stand.

${ }^{b}$ Hydralazine, methyldopa, and/or nefedipine.

\section{Provider experience and training}

Fewer doctors than midwives participated in the study (82 and 142, respectively), but all were female, by cultural preference. Only a small proportion of the providers (27\% of doctors and $14 \%$ of midwives) worked at large regional and specialized hospitals (Table 2). The median years of experience offering EmONC services was five years for doctors and four years for midwives; their training, experience, and confidence levels in providing focused ANC were also similar.

There was no significant difference in the proportion of doctors and midwives who had received in-service training on the use of $\mathrm{MgSO}_{4}$ to treat severe $\mathrm{PE} / \mathrm{E}(82 \%$ and $79 \%$ ). Doctors had administered anticonvulsants to significantly more women than the midwives had, on average, in the preceding three months (median of five and three women, respectively). However, individual providers had widely varying experience with anticonvulsants: the number of women to whom they had given anticonvulsants in the past three months ranged from a low of zero to a high of 65 . Providers' confidence in their ability to administer anticonvulsants was generally high:
$83 \%$ of doctors and $79 \%$ of midwives said they felt very confident. However, almost twice as many midwives as doctors $(16 \%$ versus $8.5 \%, \mathrm{p}<0.01)$ expressed some reservations, saying they were in need of coaching.

\section{Case management}

Providers' knowledge and decision-making skills related to severe $\mathrm{PE} / \mathrm{E}$ were tested with a case scenario describing a pregnant woman who came to the emergency department after having convulsions at home. Each part of the scenario is described in detail below.

Part one asked providers what information must be obtained immediately in order to initiate emergency management of the woman's most urgent condition. A large majority of doctors and midwives (from $83.6 \%$ to $96.9 \%$ ) correctly identified three pieces of information on the woman's status: vital signs, level of consciousness, and presence of current convulsions (Table 3). There were no significant differences by provider type. Knowledge was significantly higher among providers who had received training on $\mathrm{MgSO}_{4}$ compared to untrained providers for presence of current convulsions $(69.4 \%$ versus $90.5 \%, \mathrm{p}<$ 
Table 2 Providers' workplace, experience, and training, by provider type

\begin{tabular}{|c|c|c|c|}
\hline & Doctors $(n=82)$ & Midwives $(n=142)$ & p-value \\
\hline \multicolumn{4}{|l|}{ Location of work (\%) } \\
\hline $\mathrm{CHC}$ or district hospital & 30.4 & 44.5 & 0.079 \\
\hline Provincial hospital & 43.0 & 41.6 & \\
\hline Regional hospital or specialized hospital & 26.5 & 13.9 & \\
\hline Years of experience offering EmONC: median (range) & $5(1-22)$ & $4(1-32)$ & 0.781 \\
\hline \multicolumn{4}{|l|}{ Focused ANC } \\
\hline Has received training (\%) & 77.6 & 81.2 & 0.430 \\
\hline Number of cases attended in last 3 months: median (range) ${ }^{\mathbf{a}}$ & $60(0-900)$ & $100(0-855)$ & 0.0903 \\
\hline \multicolumn{4}{|l|}{ Confidence in providing care (\%): } \\
\hline Very confident & 86.7 & 87.4 & 0.896 \\
\hline Somewhat confident (needs coaching) & 12.0 & 11.1 & \\
\hline Not confident & 1.3 & 1.5 & \\
\hline \multicolumn{4}{|l|}{ Treatment of severe $\mathrm{PE} / \mathrm{E}$} \\
\hline Has received training on $\mathrm{MgSO}_{4}(\%)$ & 82.1 & 78.6 & 0.714 \\
\hline Number of cases given anticonvulsants in last 3 months: median (range) ${ }^{\mathbf{a}}$ & $5(0-65)$ & $3(0-50)$ & 0.031 \\
\hline \multicolumn{4}{|l|}{ Confidence in administering anticonvulsants (\%): } \\
\hline Very confident & 83.1 & 79.2 & 0.01 \\
\hline Somewhat confident (needs coaching) & 8.5 & 16.0 & \\
\hline Not confident & 8.5 & 4.8 & \\
\hline
\end{tabular}

${ }^{a} n=76$ doctors and 135 midwives for number of cases attended in last 3 months.

0.001). Knowledge on level of consciousness was significantly lower at $\mathrm{CHCs}$ and district hospitals than at provincial hospitals or at regional and specialized hospitals (80.3\% versus $93.3 \%$ and $90.9 \%, \mathrm{p}<0.05)$.

Part two asked providers to diagnose the woman's condition based on the results of a clinical exam. The correct answer, eclampsia, was given by $77.2 \%$ of doctors and $62.3 \%$ of midwives. All but two of the remaining providers diagnosed pre-eclampsia instead. There were no significant differences in diagnosis by provider type, training, or facility type.

Part three asked providers to select appropriate actions to manage the most urgent presenting condition. A large majority (96.2\% of doctors and $88.5 \%$ of midwives) recognized the need to give $\mathrm{MgSO}_{4}$, but less than half (44.3\% of doctors and $42.5 \%$ of midwives) noted the need for continuous bedside care until the woman is stable with hourly observations thereafter. Providers trained on the use of $\mathrm{MgSO}_{4}$ were significantly more likely than others to identify the need for the drug (93.3\% versus $82.3 \%, \mathrm{p}<0.05)$, but were less likely to select continuous bedside care followed by hourly observations (58.3\% versus $38.2 \%, \mathrm{p}<$ 0.05). Providers working at $\mathrm{CHCs}$ and district hospitals were significantly less likely than providers at larger facilities to recognize the need for bed rest (31.4\% versus $53.7 \%$ and $50 \%, \mathrm{p}<0.01)$.

Part four asked what immediate actions providers should take if a woman had a convulsion at the time of admission. Over four-fifths of providers (81.3\% to $88.6 \%)$ said to administer oxygen and to place the woman in a side-lying position; slightly fewer (75\% to $79.2 \%$ ) said to protect the woman from injury. There were no significant differences by provider type, training, or facility type. Notably, around half of providers ( $42 \%$ of doctors and $58 \%$ of midwives, $\mathrm{p}<0.05)$ mentioned the need for intravenous diazepam, a second-line drug recommended only in the absence of $\mathrm{MgSO}_{4}$; there was no significant difference by facility type (data not shown). Providers who received training on $\mathrm{MgSO}_{4}$ were less likely than other providers to call for giving diazepam (38\% versus $53 \%)$, but the difference was not statistically significant.

Part five asked providers which equipment and supplies must be available to best manage the woman's most urgent condition. A large majority (from $78 \%$ to $91 \%$ ) correctly identified an IV line, urinary catheter, suction catheter, and oxygen. There was no significant difference between doctors and midwives, but providers trained on $\mathrm{MgSO}_{4}$ were significantly more likely than others to identify oxygen and an adult mask (89\% versus $77 \%, \mathrm{p}<0.05)$. Providers working at $\mathrm{CHCs}$ and district hospitals were significantly less likely than those at larger facilities to identify urinary catheters (74.4\% versus $90.5 \%$ and $89.4 \%, \mathrm{p}<$ $0.01)$ and suction catheters $(68.6 \%$ versus $87.4 \%$ and $92.1 \%, \mathrm{p}<0.001)$. Many providers $(39 \%$ of doctors and $55 \%$ of midwives) also believed that it was essential to have equipment available to administer intravenous diazepam, 
Table 3 Case management: percentage of providers responding correctly to case scenario related to severe pe/e symptoms, by provider type, provider training, and facility type

\begin{tabular}{|c|c|c|c|c|c|c|c|c|c|c|}
\hline \multirow[b]{2}{*}{ Correct responses to case scenario } & \multicolumn{3}{|c|}{ Provider type } & \multicolumn{3}{|c|}{ Provider training } & \multicolumn{4}{|c|}{ Facility type } \\
\hline & $\begin{array}{l}\text { Doctors } \\
(n=79)\end{array}$ & $\begin{array}{l}\text { Midwives } \\
(n=139)\end{array}$ & $\begin{array}{c}\mathrm{p}- \\
\text { value }\end{array}$ & $\begin{array}{l}\text { Untrained providers } \\
\qquad(n=44)\end{array}$ & $\begin{array}{l}\text { Trained providers } \\
\qquad(n=174)\end{array}$ & $\begin{array}{c}\mathrm{p}- \\
\text { value }\end{array}$ & $\begin{array}{l}\text { CHCs and district } \\
\text { hospitals }(n=43)\end{array}$ & $\begin{array}{l}\text { Provincial hospitals } \\
\qquad(n=25)\end{array}$ & $\begin{array}{l}\text { Regional and specialized } \\
\text { hospitals }(n=10)\end{array}$ & $\begin{array}{c}\mathrm{p}- \\
\text { value }\end{array}$ \\
\hline \multicolumn{11}{|c|}{ I. Information needed immediately to start emergency management (\%) } \\
\hline Level of consciousness & 92.2 & 83.6 & 0.228 & 80.0 & 89.7 & 0.076 & 80.3 & 93.3 & 90.9 & 0.046 \\
\hline Presence of current convulsions & 88.4 & 87.3 & 0.949 & 69.4 & 90.5 & $<0.001$ & 80.0 & 92.3 & 91.1 & 0.082 \\
\hline Vital signs & 96.9 & 96.4 & 0.929 & 100.0 & 95.8 & 0.214 & 97.0 & 96.3 & 97.0 & 0.970 \\
\hline \multicolumn{11}{|l|}{ II. Diagnosis of eclampsia (\%) } \\
\hline Diagnosis of eclampsia & 77.2 & 62.3 & 0.120 & 66.7 & 67.8 & 1.000 & 60.5 & 66.3 & 81.1 & 0.282 \\
\hline \multicolumn{11}{|c|}{ III. Urgent actions to manage presenting condition (\%) } \\
\hline Bed rest ${ }^{a}$ & 44.3 & 42.5 & 0.725 & 58.3 & 38.2 & 0.019 & 31.4 & 53.7 & 50.0 & 0.008 \\
\hline $\mathrm{MgSO}_{4}$ & 96.2 & 88.5 & 0.051 & 82.3 & 93.3 & 0.035 & 87.2 & 92.6 & 94.7 & 0.297 \\
\hline \multicolumn{11}{|c|}{ IV. Immediate actions if woman is having convulsions when admitted (\%) } \\
\hline Give oxygen at $4-6 \mathrm{~L}$ per min. & 88.6 & 81.3 & 0.153 & 83.3 & 86.0 & 0.638 & 79.1 & 85.3 & 92.1 & 0.171 \\
\hline Place in side-lying position & 88.6 & 85.6 & 0.622 & 77.1 & 87.6 & 0.098 & 83.7 & 92.6 & 78.9 & 0.062 \\
\hline Protect woman from injury & 79.2 & 75.0 & 0.696 & 75.0 & 75.8 & 1.000 & 68.6 & 78.9 & 86.8 & 0.064 \\
\hline \multicolumn{11}{|c|}{ V. Essential equipment and supplies to manage most urgent condition (\%) } \\
\hline IV with saline or Ringers Lactate & 78.4 & 87.7 & 0.070 & 83.3 & 83.7 & 0.823 & 83.7 & 86.3 & 76.3 & 0.372 \\
\hline Indwelling urinary catheter/ bag & 87.0 & 83.1 & 0.361 & 85.4 & 82.6 & 0.830 & 74.4 & 90.5 & 89.4 & 0.008 \\
\hline Suction and suction catheter & 87.3 & 78.2 & 0.098 & 68.8 & 76.4 & 0.335 & 68.6 & 87.4 & 92.1 & 0.001 \\
\hline Oxygen and adult mask & 91.1 & 84.2 & 0.142 & 77.1 & 88.8 & 0.049 & 82.6 & 87.4 & 86.8 & 0.633 \\
\hline \multicolumn{11}{|c|}{ VI. Appropriate actions after convulsions are controlled (\%) } \\
\hline Repeat dose of $\mathrm{MgSO}_{4}$ in 4 hours & 71.4 & 77.9 & 0.301 & 64.6 & 77.5 & 0.083 & 74.4 & 73.7 & 84.2 & 0.409 \\
\hline Continue anti-hypertensives & 81.0 & 66.2 & 0.024 & 56.3 & 74.7 & 0.016 & 70.9 & 67.4 & 81.6 & 0.072 \\
\hline Monitor labor, begin partograph & 79.2 & 80.9 & 0.532 & 77.3 & 81.4 & 0.672 & 72.1 & 89.5 & 79.0 & 0.262 \\
\hline $\begin{array}{l}\text { Check respirations hourly (auscultate } \\
\text { lungs if needed) }\end{array}$ & 59.5 & 54.7 & 0.683 & 35.4 & 61.8 & 0.002 & 50.0 & 62.1 & 60.1 & 0.012 \\
\hline Document intake/output hourly & 75.9 & 69.1 & 0.269 & 68.8 & 71.4 & 0.854 & 62.8 & 76.8 & 73.7 & 0.232 \\
\hline \multicolumn{11}{|c|}{ VII. Appropriate actions after vaginal delivery (\%) } \\
\hline Continue $\mathrm{MgSO}_{4}$ for 24 hours & 80.5 & 77.2 & 0.995 & 72.7 & 80.8 & 0.302 & 72.1 & 83.2 & 84.2 & 0.130 \\
\hline $\begin{array}{l}\text { Assess vital signs every } 15 \text { minutes } \\
\text { for } 2 \text { hours after birth }\end{array}$ & 90.9 & 90.4 & 0.652 & 88.6 & 91.6 & 0.771 & 91.9 & 92.6 & 84.2 & 0.288 \\
\hline
\end{tabular}

Bed rest is interpreted as continuous care in a bed near staff until she is stable, with hourly observations thereafter. 
and there was no significant difference by facility type or provider training (data not shown).

Part six asked providers what actions were appropriate one hour following the initiation of treatment if the woman still had a moderate headache but no further convulsions. From $55 \%$ to $81 \%$ of providers identified each of the five correct responses. Doctors were significantly more likely than midwives to recognize the need to continue use of anti-hypertensives to maintain diastolic blood pressure between $90-100 \mathrm{~mm} \mathrm{Hg}$ (81\% versus 66.2\%, $\mathrm{p}<0.05$ ). Trained providers were significantly more likely than others to identify continued use of anti-hypertensives $(74.7 \%$ versus $56.3 \%, \mathrm{p}<0.05)$ and checked respirations every hour, auscultating the lungs if necessary (35.4\% versus $61.8 \%, \mathrm{p}<0.001)$. Regularly checking the respiratory rate is especially important because most health facilities in Afghanistan lack oximeters to check oxygen saturation.

The final part of the scenario asked providers what actions were appropriate after the woman had a spontaneous vaginal delivery. A large majority of providers recognized the need to continue $\mathrm{MgSO}_{4}$ for 24 hours after birth (80.5\% of doctors and $77.2 \%$ of midwives) and assess vital signs every 15 minutes during the first two hours after birth ( $90.9 \%$ of doctors and $90.4 \%$ of midwives). There were no significant differences by provider type, facility type, or provider training.

Overall, providers who had been trained on the treatment of severe PE/E scored significantly higher than untrained providers on six out of 20 items in the case scenario. There were significant differences by facility type for five out of the 20 items; providers at $\mathrm{CHCs}$ and district hospitals scored lower than providers at larger hospitals. Finally, there was a significant difference between doctors and midwives on just one item: continued use of antihypertensives after convulsions are controlled.

\section{Discussion}

Most women in Afghanistan deliver at home and must overcome long distances, difficult terrain, poor roads, and limited transportation to get to health facilities if they suffer complications [16]. It is essential that providers have the knowledge, skills, supplies, and equipment needed to immediately diagnose and address complications. Our findings show that most EmONC facilities and providers in Afghanistan are relatively well-prepared to manage severe PE/E cases, but certain weaknesses need to be addressed.

Managing hypertension and preventing convulsions are key elements in treating severe PE/E. All assessed facilities had blood pressure cuffs and stethoscopes on hand, and a large majority had anti-hypertensive drugs in stock. However, the case scenario found that about one-fifth of doctors and one-third of midwives did not correctly identify the need to continue administering anti-hypertensives after delivery in cases of PE/E. This finding suggests that a substantial portion of women with PE/E may not be treated for hypertension after delivery.

While any of several anti-hypertensive drugs may be used to treat severe PE/E [7], $\mathrm{MgSO}_{4}$ is the clear drug of choice to prevent convulsions, and its potential impact on maternal morbidity and mortality is considerable. In Nigeria, for example, the case fatality rate for severe PE/E at hospitals in Kano fell from $20.9 \%$ to $2.3 \%$ after $\mathrm{MgSO}_{4}$ was introduced; perinatal mortality also fell significantly [17]. The drug has been identified in a list of 13 affordable, effective, but underutilized lifesaving commodities by the United Nations Commission on Life-Saving Commodities for Women and Children [18].

However, this study found that many EmONC facilities in Afghanistan-including half of provincial, specialized, and regional hospitals-are continuing to administer diazepam to some patients with severe $\mathrm{PE} / \mathrm{E}$. The transition from using diazepam to using $\mathrm{MgSO}_{4}$ in the treatment of severe $\mathrm{PE} / \mathrm{E}$ has lagged in many countries. Common obstacles include inappropriate policies, limited supplies, lack of training, and misperceptions about use of $\mathrm{MgSO}_{4}$ [19]. A 2012 survey of 37 countries suggested that policy for and access to $\mathrm{MgSO}_{4}$ is improving, but that additional support is needed regarding provider competence and confidence in its use [20]. In Afghanistan, policy does not present a barrier to the use of $\mathrm{MgSO}_{4}$ because national guidelines exist and $\mathrm{MgSO}_{4}$ is included in the MoPH's Essential Drug List. Our findings indicate that supply is not a major problem either, given that the drug was in stock at nearly all assessed facilities. Rather, the case scenario suggests that confusion remains in the minds of many providers regarding the role of diazepam.

Training on the use of $\mathrm{MgSO}_{4}$-part of in-service EmONC training for midwives and doctors in Afghanistanwas associated with better decision-making on six items in the case scenario. However, training did not make a significant difference in providers' decisions on diazepam, in part because the EmONC training package identifies diazepam as an alternative drug for the management of severe $\mathrm{PE} / \mathrm{E}$ when $\mathrm{MgSO}_{4}$ is not available. Two dozen other countries also have concurrent approval of diazepam and $\mathrm{MgSO}_{4}$ as first-line anticonvulsants, which present a potentially confusing scenario for health care providers [20]. Lack of understanding of how $\mathrm{MgSO}_{4}$ should be administered and persistent concerns about side effects, despite evidence of the drug's safety in low-resource settings, also contribute to providers' reluctance to administer the drug [21]. Further refresher training, accompanied by posttraining follow-up, supportive supervision, consistent training manuals and job aids, is essential to help Afghan providers understand that $\mathrm{MgSO}_{4}$ is safe and should be preferred over diazepam whenever it is available. But studies suggest that training alone may not be sufficient to 
change providers' use of anticonvulsants. In Nepal, for example, a training intervention on severe PE/E raised providers' test scores, but they remained hesitant about administering $\mathrm{MgSO}_{4}$ [22]. Without a ready supply of $\mathrm{MgSO}_{4}$, an easily accessible treatment protocol, supervision, and reinforcement of best practices after training, providers may not change established prescribing habits and switch from diazepam to $\mathrm{MgSO}_{4}$.

Low caseloads may blunt the impact of training, and sustaining competence with limited opportunities to practice is a challenge. In Zambia, for example, where lack of in-service training posed a barrier to the use of $\mathrm{MgSO}_{4}$, the infrequency of pre-eclampsia cases at small hospitals exacerbated the problem by limiting providers' exposure to the condition and opportunity to practice [23]. Our data suggest that this is potentially a problem at $\mathrm{CHCs}$ and district hospitals in Afghanistan, which may see only a handful of cases of severe PE/E each year. Providers working at smaller facilities also tend to have limited opportunities for learning and few, if any, colleagues to confer with. These disadvantages may explain why providers at $\mathrm{CHCs}$ and district hospitals scored significantly lower on five items in the clinical scenario. Providers at these facilities would benefit from regular refresher courses that include clinical simulations on severe $\mathrm{PE} / \mathrm{E}$, along with ready access to job aids, decision-making charts, and fully equipped emergency kits [24]. In Senegal, clinical audits of charts for all pregnant women with hemorrhagic and hypertensive complications also promoted correct diagnosis and treatment [25].

While providers scored well on many areas in the case scenario, there is room for improvement, especially in managing patients with eclampsia after convulsions are controlled. The need to strengthen knowledge on severe PE/E is not unique to Afghanistan: in an evaluation of skilled birth attendants in Benin, Ecuador, Jamaica, and Rwanda, mean knowledge scores for pregnancy-induced hypertension ranged from $52 \%$ to $78 \%$. There was greater disparity in doctors' and midwives' knowledge of hypertension (75\% and $58 \%$, respectively) than their knowledge of other topics [26]. This finding stands in marked contrast to the situation in Afghanistan, where doctors and midwives had similar scores on the case scenario and shared the same strengths and weaknesses, with one exception (continuing to use anti-hypertensives to maintain diastolic pressure after convulsions are controlled). The similarity in the capacity of doctors and midwives is notable and somewhat unique. It may be due to the team approach to in-service EmONC training adopted by the $\mathrm{MoPH}$, and increasingly common globally, which can help different health cadres understand each other's roles and promote greater collaboration and more effective teamwork [24].

While this study focuses on appropriate treatment of severe $\mathrm{PE} / \mathrm{E}$, reducing morbidity and mortality requires action outside of-and long before women arrive at-
EmONC facilities. For example, calcium supplementation during pregnancy can prevent $\mathrm{PE} / \mathrm{E}$ in countries like Afghanistan, where pregnant women get little calcium as part of their diet $[7,27]$. Likewise, routinely screening for hypertension, proteinuria, and danger signs during ANC visits can detect cases of pre-eclampsia and prevent them from progressing to eclampsia [27-29]. Raising community awareness of warning signs of eclampsia, such as headache, visual disturbances, and epigastric pain, can prompt women to seek care in a timely manner $[17,30]$. The weaknesses identified in the management of severe PE/E cases at EmONC facilities suggest that frontline health workers in Afghanistan may also suffer from limited knowledge, skills, and supplies. Further research on the capacity of community health workers who provide ANC in the community and at health posts in Afghanistan is needed to complement this study.

\section{Study strengths and limitations}

This study used a case scenario to assess providers' capacity to manage severe PE/E cases. Clinical vignettes of this kind are a validated method to assess the quality of clinical practice that has been applied in both low- and high-income countries [31,32]. They provide a simple and inexpensive way to assess how well providers apply knowledge and decision-making skills to realistically complex scenarios and have proven especially useful for comparing sites and settings. In this study, use of a case scenario permitted us to measure the impact of the facility setting and provider characteristics on case management.

Interpretation of the findings is subject to certain limitations. First, the assessment is not representative of the entire country, because security concerns limited the number and locations of facilities assessed. Second, the sampling strategy underrepresented providers at larger facilities who may have stronger skills, although fewer providers were selected from $\mathrm{CHCs}$ and district hospitals than provincial, regional, and specialized facilities. Third, no validity study has been conducted on the case scenario used in this assessment, although the tool was based on best practices. Fourth, it is not possible for a single case scenario to test providers' case management skills in a variety of situations as, for example, when a woman develops severe PE/E postpartum. Fifth, contradictions between different information sources, such as interviews and registers, suggest that data on services offered at each facility may be subject to recall and reporting bias.

\section{Conclusions}

Drugs and supplies to treat severe PE/E are widely available at EmONC facilities in Afghanistan, but providers' knowledge is insufficient in some areas, especially regarding the decision to use $\mathrm{MgSO}_{4}$ instead of diazepam. Providers who have received specific training on PE/E or who 
work at larger facilities and who see more women with severe $\mathrm{PE} / \mathrm{E}$ proved to have stronger case management skills. This suggests a need to: clarify service delivery guidelines, especially regarding anticonvulsants, and revise job aids and training materials accordingly; offer refresher training to providers who work at facilities with low caseloads; and reinforce best practices with supervision and other reinforcement activities. In particular, training efforts should place further emphasis on the superiority of MgSO4 over diazepam and on the need to continue antihypertensive treatment after delivery. The study findings will be used to help inform continuing education and reinforcement efforts in Afghanistan and also to standardize supplies and equipment across different facility levels. More broadly, they can contribute to the development of effective strategies for translating health worker knowledge into practice in low-income countries.

\section{Additional file}

Additional file 1: Case Scenario. EmONC Needs Assessment in Afghanistan: Clinical Decision-Making Case Scenario 1. Care to Mother in Maternity Ward - Headache, blurred vision, convulsions or loss of consciousness, elevated blood pressure.

\section{Abbreviations}

ANC: Antenatal care; CHC: Comprehensive health center; EmONC: Emergency obstetric and newborn care; MCHIP: Maternal and Child Health Integrated Program; $\mathrm{MgSO}_{4}$ : Magnesium sulfate; $\mathrm{MoPH}$ : Ministry of public health of Afghanistan; NGO: Nongovernmental organization; PE/E: Pre-eclampsia/ eclampsia; WHO: World health organization.

\section{Competing interests}

The authors declare that they have no competing interests.

\section{Authors' contributions}

YMK designed the study, served as the Principal Investigator, and coordinated the manuscript drafting and finalization process. NA participated in the design and implementation of the study, contributed to the analysis and interpretation of study findings, and revision of the manuscript. AK contributed to the interpretation of study findings, writing, and revision of the manuscript. HT conducted the data analysis and contributed to the interpretation of study findings, writing, and revision of the manuscript. SC contributed to interpretation of study findings, writing, and revision of the manuscript. PM participated in the design and implementation of the study, contributed to the analysis and interpretation of study findings, and revision of the manuscript. PB, JVR, and JS participated in critical review of the manuscript and provided key input into the interpretation of study findings, discussion, and conclusions. All authors read and approved the final manuscript.

\section{Acknowledgements}

The authors would like to thank UNICEF for funding this study and technical collaboration, the central and provincial offices of the MoPH for their guidance and support, and the many health professionals who participated in the study. The authors would also like to extend our thanks to all of the midwives and doctors who served as data collectors in very difficult circumstances and the NGOs implementing Afghanistan's Basic Package of Health Services. Finally, the authors would like to acknowledge the support of the Afghan Midwifery Association; Malalai Naziri (UNICEF); Sadia Ayubi (MoPH); Denise Byrd, Hannah Gibson, Manizha Faqir, Mohammed Masood Arzoly, Khalid Yari, Mahmood Azimi, Liza Hashemi, Zahera Sediqqi, Matiullah Noorzad, Abdul Qader Rahimi, Adela Kohistani, Rahela Joya, Akmal Samsor, and Humaira Alawi (Jhpiego/Afghanistan); and Jaime Mungia, Harshad Sanghvi, Patricia Gomez, Eva Bazant, and Sue Tredwell (Jhpiego/Baltimore).

\section{Author details}

'Jhpiego/USA, an affiliate of Johns Hopkins University, 1615 Thames Street, Baltimore, MD 21231, USA. ${ }^{2}$ Jhpiego/Afghanistan, an affiliate of Johns Hopkins University, Baltimore, MD, USA. ${ }^{3}$ Johns Hopkins Bloomberg School of Public Health (JHSPH), Baltimore, USA. ${ }^{4} \mathrm{FHI} 360$ and Averting Maternal Death and Disability, Washington, USA. ${ }^{5}$ Free University, Amsterdam, The Netherlands. ${ }^{6}$ Department of Obstetrics \& Gynecology, Leeuwarden Medical Center, Leeuwarden, The Netherlands.

\section{Received: 2 April 2013 Accepted: 10 October 2013}

Published: 12 October 2013

\section{References}

1. Khan KS, Wojdyla D, Say L, Gülmezoglu AM, Van Look PF: WHO analysis of causes of maternal death: a systematic review. Lancet 2006, 367:1066-1074.

2. Steegers EA, von Dadelszen P, Duvekot JJ, Pijnenborg R: Pre-eclampsia. Lancet 2010, 376:631-644.

3. Myatt L, Clifton RG, Roberts JM, Spong CY, Hauth JC, Varner MW, Thorp JM Jr, Mercer BM, Peaceman AM, Ramin SM, Carpenter MW, lams JD, Sciscione A, Harper M, Tolosa JE, Saade G, Sorokin Y, Anderson GD: First-trimester prediction of preeclampsia in nulliparous women at low risk. Obstet Gynecol 2012, 119:1234-1242.

4. Goldenberg RL, McClure EM, Macguire ER, Kamath BD, Jobe AH: Lessons for low-income regions following the reduction in hypertension-related maternal mortality in high-income countries. Int J Gynaecol Obstet 2011, 113(2):91-95.

5. Ronsmans C, Campbell O: Quantifying the fall in mortality associated with interventions related to hypertensive diseases of pregnancy. BMC Public Health 2011, 11(Suppl 3):S8

6. Koopmans CM, Bijlenga D, Groen H, Vijgen SM, Aarnoudse JG, Bekedam DJ, van den Berg PP, de Boer K, Burggraaff JM, Bloemenkamp KW, Drogtrop AP, Franx A, de Groot CJ, Huisjes AJ, Kwee A, van Loon AJ, Lub A, Papatsonis DN, van der Post JA, Roumen FJ, Scheepers HC, Willekes C, Mol BW, van Pampus MG, HYPITAT study group: Induction of labour versus expectant monitoring for gestational hypertension or mild pre-eclampsia after 36 weeks' gestation (HYPITAT): a multicentre, open-label randomised controlled trial. Lancet 2009, 374:979-988.

7. World Health Organization (WHO): WHO recommendations for prevention and treatment of Pre-eclampsia and eclampsia. Geneva: World Health Organization; 2011

8. Duley $\mathrm{L}$, Henderson-Smart D: $\mathrm{MgSO}_{4}$ versus diazepam for eclampsia. Cochrane Database Syst Rev 2003, 4:Art. No CD000127.

9. Altman D, Carroli G, Duley L, et al: Do women with pre-eclampsia, and their babies, benefit from $\mathrm{MgSO}_{4}$ ? The Magpie Trial: a randomized placebo-controlled trial. Lancet 2002, 359:1877-1890.

10. The Eclampsia Trial Collaborative Group: Which anticonvulsant for women with eclampsia? Evidence from the Collaborative Eclampsia Trial. Lancet 1995, 345:1455-1463.

11. Afghan Public Health Institute, Ministry of Public Health (APHI/MoPH), Central Statistics Organization (CSO) [Afghanistan], ICF Macro, Indian Institute of Health Management Research (IIHMR), and World Health Organization Regional Office for the Eastern Mediterranean (WHO/EMRO): Afghanistan mortality survey 2010. Calverton, Maryland: ICF Macro; 2011.

12. Central Statistics Organisation (CSO) [Afghanistan] and UNICEF: Afghanistan multiple indicator cluster survey 2010-2011: final report. Kabul: UNICEF; 2012.

13. UNICEF, Jhpiego, Ministry of Public Health (MoPH) [Aghanistan]: Emergency Obstetric and Neonatal Care (EmONC) needs assessment in Afghanistan. Kabul: UNICEF; 2010.

14. Kim YM, Zainullah P, Mungia J, Tappis H, Bartlett L, Zaka N: Availability and quality of emergency obstetric and neonatal care services in Afghanistan. Int J Gynecol Obstet 2012, 116:192-196.

15. Averting Maternal Death and Disability Program (AMDD): Needs Assessment of Emergency Obstetric and Newborn Care (EmONC): facilitator's guide. New York: Averting Maternal Death and Disability; 2009.

16. Hirose A, Borchert M, Niksear H, Alkozai AS, Gardiner J, Fillippi V: The role of care-seeking delays in intrauterine fetal deaths among 'near-miss' women in Herat, Afghanistan. Paediatr Perinat Epidemiol 2012, 26:388-397.

17. Tukur J, Ahonsi B, Mohammed Ishaku S, Araoyinbo I, Okereke E, Babatunde AO: Maternal and fetal outcomes after introduction of $\mathrm{MgSO} 4$ for treatment of preeclampsia and eclampsia in selected secondary facilities: a low-cost intervention. Matern Child Health J 2012. Epub ahead of print. 
18. United Nations Commission on Life-Saving Commodities for Women and Children: Life-saving commodities. http://www.everywomaneverychild.org/ resources/un-commission-on-life-saving-commodities/life-saving-commodities.

19. EngenderHealth: Balancing the scales: expanding treatment for pregnant women with life-threatening hypertensive conditions in developing countries. New York: EngenderHealth; 2007.

20. Smith J, Currie S, Perri J, Bluestone J, Cannon T: National programs for the prevention and management of postpartum hemorrhage and Pre-eclampsia leclampsia: a global survey 2012. Maternal and Child Health Integrated Program: Washington, DC; 2012

21. Smith JM, Lowe RF, Fullerton J, Currie SM, Harris L, Felker-Kantor E: An integrative review of the side effects related to the use of $\mathrm{MgSO} 4$ for pre-eclampsia and eclampsia management. BMC Pregnancy Childbirth 2013, 13:34.

22. Dhakal $\mathrm{G}$, Subedi $\mathrm{M}$, Paudel $\mathrm{K}: \mathrm{MgSO}_{4}$ in management of severe pre-eclampsia and eclampsia. J Nepal Health Res Counc 2012, 10(21):113-117.

23. Ridge $A L$, Bero LA, Hill SR: Identifying barriers to the availability and use of $\mathrm{MgSO}_{4}$ Injection in resource poor countries: a case study in Zambia. BMC Health Serv Res 2010, 10:340.

24. Frenk J, Chen L, Bhutta ZA, Cohen J, Crisp N, Evans T, Fineberg H, Garcia P, Ke Y, Kelley P, Kistnasamy B, Meleis A, Naylor D, Pablos-Mendez A, Reddy S, Scrimshaw S, Sepulveda J, Serwadda D, Zurayk H: Health professionals for a new century: transforming education to strengthen health systems in an interdependent world. Lancet 2010, 376:1923-1958.

25. Dumont A, Gaye A, Mahé P, Bouvier-Colle MH: Emergency obstetric care in developing countries: impact of guidelines implementation in a community hospital in Senegal. BJOG 2005, 112:1264-1269.

26. Harvey SA, Ayabaca P, Bucagu M, Djibrina S, Edson WN, Gbangbade S, McCaw-Binns A, Burkhalter BR: Skilled birth attendant competence: an initial assessment in four countries, and implications for the safe motherhood movement. Int J Gynaecol Obstet 2004, 87:203-210.

27. Firoz T, Sanghvi H, Merialdi M, von Dadelszen P: Pre-eclampsia in low and middle income countries. Best Pract Res Clin Obstet Gynaecol 2011, 25:537-548.

28. Gaym A, Bailey P, Pearson L, Admasu K, Gebrehiwot Y: Ethiopian National EmONC assessment team. Disease burden due to pre-eclampsia /eclampsia and the Ethiopian health system's response. Int J Gynaecol Obstet 2011, 115:112-6.

29. McCaw-Binns AM, Ashley DE, Knight LP, MacGillivray I, Golding J: Strategies to prevent eclampsia in a developing country: I Reorganization of maternity services. Int J Gynaecol Obstet 2004, 87(3):286-94.

30. MacGillivray I, McCaw-Binns AM, Ashley DE, Fedrick A, Golding J: Strategies to prevent eclampsia in a developing country: II. Use of a maternal pictorial card. Int I Gynaecol Obstet 2004, 87:295-300.

31. Peabody JW, Liu A: A cross-national comparison of the quality of clinical care using vignettes. Health Policy Plan 2007, 22(5):294-302.

32. Peabody JW, Luck J, Glassman P, Jain S, Hansen J, Spell M, Lee M: Measuring the quality of physician practice by using clinical vignettes: a prospective validation study. Ann Intern Med 2004, 141:771-80

doi:10.1186/1471-2393-13-186

Cite this article as: Kim et al:: Prevention and management of severe pre-eclampsia/eclampsia in Afghanistan. BMC Pregnancy and Childbirth 2013 13:186

\section{Submit your next manuscript to BioMed Central and take full advantage of:}

- Convenient online submission

- Thorough peer review

- No space constraints or color figure charges

- Immediate publication on acceptance

- Inclusion in PubMed, CAS, Scopus and Google Scholar

- Research which is freely available for redistribution 